\title{
Estudo microscópico e macroscópico, com enfoque radiográfico e de alizarina, no desenvolvimento embrionário e fetal de gatos domésticos (Felis catus) em diferentes idades gestacionais ${ }^{1}$
}

\author{
Dilayla K. Abreu², Elaine A.F. Rodrigues ${ }^{2}$, Janaina M. Monteiro², André \\ L. Franciolli ${ }^{2}$, Carolina Costola-Souza ${ }^{3}$, Kelly C.S. Roballo ${ }^{4}$, Carlos Eduardo \\ Ambrósio $^{4^{*}}$ e Maria Angélica Miglino ${ }^{2}$
}

\begin{abstract}
Abreu D.K., Rodrigues E.A.F., Monteiro J.M., Franciolli A.L., Costola-Souza C., Roballo K.C.S., Ambrósio C.E. \& Miglino M.A. 2011. [Microscopic and macroscopic study focusing ray and alizarin on embryonic and fetal development in cats (Felis catus) in different gestational ages.] Estudo microscópico e macroscópico, com enfoque radiográfico e de alizarina, no desenvolvimento embrionário e fetal de gatos domésticos (Felis catus) em diferentes idades gestacionais. Pesquisa Veterinária Brasileira 31(Supl.1):57-66. Setor de Anatomia dos Animais Domésticos e Silvestres, Faculdade de Medicina Veterinária e Zootecnia, Universidade de São Paulo, Av. Prof. Dr. Orlando Marques de Paiva 87, Cidade Universitária, São Paulo, SP 05508-270, Brazil. E-mail: ceambrosio@usp.br

The domestic cat was named Felis catus by Carolus Linnaeus in his book Systema Naturae, in 1798. The family Felidae has many morphological similarities with wild felines. The study of the embryology of the domestic cat is of great value considering its importance as an experimental model for the wild cats endangered from extinction, especially in the research related to reproductive biology. The objective of this study is the descriptive embryology of the domestic cat at different stages of pregnancy, through macroscopic description of photographic records, radiographic and alizarin technique, and microscopic description of photographic records by light microscopy. In embryos with an estimated gestational age of 17 days we observed macroscopically an expansion corresponding to the rostral forebrain, the placoid site of lens, cervical flexure, the four pharyngeal arches with grooves dividing the cardiac prominence, a sign of the limb bud, and the presence of somites. In the caudal region of the embryo, we saw the cranio-caudal bend, allowing the same position in format of a " $\mathrm{C}$ ". In embryos with an estimated age of 22 days, we noticed macroscopically the forebrain, optic vesicle pigmentation of the retina, the optic vesicle, fourth ventricle, liver, fore and hind limbs with a slight distinction between the digits and superficial vascularization. In embryos with an estimated age of 25 days we noticed presence of the forebrain and midbrain, the pronounced cervical curvature of the optic vesicle with strong pigmentation of the retina, the optic vesicle, limbs and chest well developed, distinguishing the digits and pronounced the liver Fetuses with estimated age of 52 days have internal and external structures easily identified in adult animals. With respect to the bone structure we noted that they did not have any radial bone formed, only bone shafts. Microscopically, the embryo of the domestic cat with CR of $0.9 \mathrm{~cm}$ and estimated age of 19 days revealed the presence of beak, oral cavity with upper and lower nasal cavity, eye and opening of the $4^{\text {th }}$ ventricle of the brain, esophagus, heart with atrium and ventricle, lung, liver, mesonephric ridge, primitive gonad, stomach,
\end{abstract}

\footnotetext{
${ }^{1}$ Recebido em 6 de julho de 2011.

Aceito para publicação em 29 de novembro de 2011.

${ }^{2}$ Departamento de Cirurgia, Faculdade de Medicina Veterinária e Zootecnia (FMVZ), Universidade de São Paulo (USP), Av. Prof. Dr. Orlando Marques de Paiva, 87, São Paulo, SP 05508-000, Brasil.
}

\footnotetext{
${ }^{3}$ Depto Patologia Experimental e Comparada, FMVZ, USP, São Paulo, SP.

${ }^{4}$ Departamento de Ciências Básicas, Faculdade de Zootecnia e Engenharia de Alimentos, Universidade de São Paulo, Campus Pirassununga, Avenida Duque de Caxias Norte 225, ZAB, Pirassununga, SP 13635-900, Brasil. *Autor para correspondência: ceambrosio@usp.br
} 
forelimb bud, spine and spinal cord in development. This paper is of great importance for study of the internal and external morphology of domestic cats for better understanding of the embryonic development of the species.

INDEX TERMS: Domestic cat, Felis catus, embryology, histology, radiograph, Alizarin.

RESUMO.- 0 gato doméstico (Felis catus) foi nomeado por Carolus Linnaeus em seu livro Systema Naturae, em 1798. A família Felidea apresenta muita semelhança morfológica com os felinos selvagens. 0 estudo da embriologia do gato doméstico é de grande valia, uma vez que, é considerado um importante modelo animal quando comparado aos gatos selvagem em extinção, especialmente relacionado às pesquisas sobre biologia reprodutiva. Este trabalho objetivou análisar e comparar as fases embrionárias de quatro embriões e um feto de felinos domésticos. Nos embriões com idade gestacional estimada em 17 dias $(0,5 \mathrm{~cm} \mathrm{CR})$ podemos observar pela análise macroscópica a presença de dilatação rostral correspondente ao prosencéfalo, o local placóide do cristalino, a flexura cervical, os quatro arcos faríngeos com os sulcos que o dividem, a proeminência cardíaca, o indício do brotamento do membro pélvico, além da presença de somitos. Na região caudal do embrião, visualizamos a curvatura cranio-caudal, permitindo ao mesmo uma posição em formato de "C". Nos embriões com idade gestacional estimada em 22 dias $(1,2 \mathrm{~cm}$ CR), na análise macroscópica foi visualizado o prosencéfalo, vesícula óptica com pigmentação da retina, vesícula ótica, quarto ventrículo, fígado, membros torácicos e pélvicos com discreta distinção dos dígitos e vascularização superficial. Nos embriões com idade gestacional estimada em 25 dias $(1,5 \mathrm{~cm} \mathrm{CR})$ notamos a presença do prosencéfalo e mesencéfalo, a curvatura cervical pronunciada, vesícula óptica com forte pigmentação da retina, vesícula ótica, membros pélvicos e torácicos bem desenvolvidos, com distinção dos dígitos e fígado bem pronunciado. Os fetos com idade gestacional estimada em 52 dias $(10 \mathrm{~cm} \mathrm{CR})$ possuem estruturas internas e externas facilmente identificadas em animais adultos. Com relação às estruturas ósseas notamos que as mesmas não apresentam nenhuma epífise óssea formada, sendo visíveis somente as diáfises ósseas. Na análise microscópica, o embrião de idade gestacional de 19 dias $(0,9 \mathrm{~cm} \mathrm{CR})$ revelou a presença do rostro, cavidade oral com lábio superior e inferior, cavidade nasal, olho e a abertura do 4 o ventrículo encefálico, esôfago, coração com átrio e ventrículo, pulmão, fígado, crista mesonéfrica, gônada primitiva, estômago, broto do membro torácico, coluna vertebral e a medula espinhal em formação. Esse trabalho é de grande importância para o estudo da morfologia externa e interna de gatos domésticos, principalmente no que diz respeito ao desenvolvimento ósseo e articular, considerando as alterações que podem ou não ser promovidas pelo uso de terapias medicamentosas ou celulares durante o desenvolvimento embrionário e fetal.

TERMOS DE INDEXAÇÃO: Gato doméstico, Feliz catus, embriologia, histologia, radiografia, Alizarina.

\section{INTRODUÇÃO}

0 gato doméstico foi denominado Felis catus por Carolus Linnaeus na sua obra Systema Naturae, de 1798. 0 mesmo autor classificou na escala zoologia o gato pertecente ao
Reino Animalia, Filo Chordata, Classe Mammalia, Ordem Carnivora, Familia Felidae e do Genero Felis (Wilson \& Reede 2005).

Cada vez mais as pessoas trazem os animais domésticos para sua convivência, principalmente pela melhor qualidade de vida que os mesmos proporcionam aos seres humanos. Nos últimos anos, a população de gatos no Brasil tem crescido de forma acentuada e o interesse das pessoas em adquirirem felinos de raças definidas tem aumentado consideravelmente. Além de ser uma espécie que se ajusta ao estilo de vida atual, já que ocupa menos espaço que o cão e possui hábitos mais independentes, os gatos podem servir como modelo experimental para aproximadamente 36 anormalidades e defeitos metabólicos homólogos a doenças humanas (Migaki 1982). Não obstante, devido a semelhanças fisiológicas com os demais membros da família Felidae, facilidades de manejo e maior número de exemplares, o gato doméstico é um importante modelo experimental para os felinos selvagens ameaçados de extinção, especialmente nas pesquisas ligadas à biologia da reprodução.

Durante o estro a gata ovula por meio do estímulo das espículas do pênis do macho, gerando um reflexo neuroendócrino que desencadeia a liberação de LH (hormônio luteinizante) pela hipófise . A ovulação ocorre entre 24 e 42 horas após a cópula. A ovulação da gata também pode ser induzida por manipulação vaginal e por introdução de um macho em um grupo de gatos onde a fêmea esteja no cio (Moore \& Persaud, 2007). 0 período gestacional varia de 58-65 dias apresentando uma média de 62 dias (Hyttel et al. 2009).

O desenvolvimento pré-natal dos mamíferos inclui o período de fertilização até o nascimento, e é caracterizado por uma série de alterações morfológicas internas e externas, que podem ser divididas em estágios embrionários e fetais para comparações (Hyttel et al. 2010, Martins et al. 2011). Conforme Evans \& Sack (1973) o período embrionário dos gatos inicia-se no momento da implantação e vai até o vigésimo oitavo dia gestacional. A partir do vigésimo nono dia gestacional até o momento do nascimento é denominado de período fetal.

É de suma importância um estudo aprofundado da embriologia da espécie, para conhecer as possíveis interferências que esses animais podem sofrer durante o desenvolvimento gestacional mediante tratamentos medicamentosos e terapias celulares, visto que a calcificação óssea ocorre no terço final da gestação. Por este motivo optamos pelo estudo das estruturas ósseas e cartilagíneas, as quais foram realizadas pelas técnicas de Alizarina e radiografia.

\section{MATERIAL E MÉTODOS}

Foram utilizados 14 embriões e 5 fetos de gatos domésticos com idades gestacionais estimadas em 17 (E17), 19 (E19), 22 (E22), 25 dias (E25) e 52 dias (F52). Os úteros foram obtidos por cam- 
panhas de castração na cidade de Pirassununga/SP e na cidade de Guarulhos/SP. As amostras foram fixadas em solução de paraformaldeído $4 \%$ tamponado a $0,1 \mathrm{M}$ e pH 7,4, por meio da perfusão intrauterina. Após esse procedimento, os animais foram removidos para documentação fotográfica, visando sua descrição morfológica, a fim de elucidar as estruturas presentes. Após a fixação, os embriões foram pesados em uma balança analítica e mensurados com auxílio de um paquímetro, da crista nucal à última vértebra sacral (Crown-Rump), de acordo com Evans \& Sack (1973), para estimar a idade dos embriões e fetos coletados.

Para análise macroscópica, os embriões e os fetos foram fotografados em ângulos diferentes, com técnicas macroscópicas de iluminação indireta e direta.

Foi realizado também o método de Dingerkus (modificado) Alizarina cuja finalidade é corar a cartilagem em azul. Os órgãos internos, pele e tecido adiposo foram retirados dos fetos, em seguida estes permaneceram em água destilada para hidratação e lavagem. Estes foram submergidos em uma solução de corante Alcian Blue onde nesta solução, as amostras permaneceram refrigeradas. As amostras foram submetidas a uma reidratação seqüencial e cada vez que as peças afundavam, eram transferidas de solução. Decorrido esse processo foram transferidos para uma solução saturada de borato de sódio e em seguida, as peças foram transferidas para uma solução de hidróxido de potássio e corante Alizarina Red onde permaneceram nesta solução. As peças foram conservadas em glicerina com cristais de timol.

Para a realização da técnica radiográfica utilizou aparelho de Raio-X digital. Os fetos foram previamente lavados em solução de PBS $10 \%$ e posicionados laterolateralmente e ventrodorsalmente. Considerando a densidade tecidual do feto, o aparelho foi ajustado para $40 \mathrm{Kv}$ e 15 MAs. As imagens foram digitalizadas e as estruturas identificadas.

Os embriões com idade gestacional estimada em 19 dias foram destinados a microscopia de luz. Estes foram desidratados em uma série crescente de concentração de etanol, diafanizados em xilol, seguidos de inclusão em similar de parafina (Histosec $($ ). Cada bloco foi submetido a microtomia em micrótomo automático (Leica RM2165) obtendo-se cortes longitudinais de aproximadamente $5 \mu \mathrm{m}$. Os cortes, após serem desparafinizados em xilol seguidos de uma série decrescente de etanol, foram corados pela técnica de Hematoxilina e Eosina (HE) e suas características morfológicas foram fotodocumentadas em microscópio de luz (Nikon Eclipse E-800).

\section{RESULTADOS}

Para a realização da análise macroscópica, os embriões e fetos foram dissociados de suas membranas fetais. Envolvendo os embriões E17 pode-se observar uma membrana transparente discreta onde depois de removê-la foi possível visualizá-los em formato de " $\mathrm{C}$ ". Estes apresentaram $\mathrm{CR}$ variando de 0,3 a $0,5 \mathrm{~cm}$, com coloração translúcida característica de embriões, e se apresentam encurvados, especialmente em sua eminência caudal. Na região da cabeça foi possível verificar a dilatação rostral correspondente ao prosencéfalo, além do local placóide do cristalino. Notamos a presença de uma curvatura entre a parte posterior do cérebro e da medula espinhal denominada flexura cervical. Verificam-se os quatro arcos faríngeos, além dos sulcos que o dividem. Na cavidade torácica é evidente a proeminência cardíaca. Foi possível observar indício do brotamento do membro pélvico, além da presença de somitos (Fig.1A).

Os embriões E22 apresentam coloração esbranquiçada e variação de 1,1 a 1,3cm de CR. Na cabeça foi possível ob- servar a primeira vesícula encefálica, conhecida como prosencéfalo, bem como o desenvolvimento do mesencéfalo na região de cérebro posterior. Notamos a vesícula óptica com pigmentação da retina, vesícula ótica, o quarto ventrículo e uma curvatura cervical pronunciada. Na cavidade abdominal, nota-se o fígado bem pronunciado. Observa-se a presença de membros torácicos e pélvicos com discreta distinção dos dígitos. Visualizamos ainda, a vascularização superficial, a presença do cordão umbilical com vasos visíveis e do saco amniótico (Fig.1B).
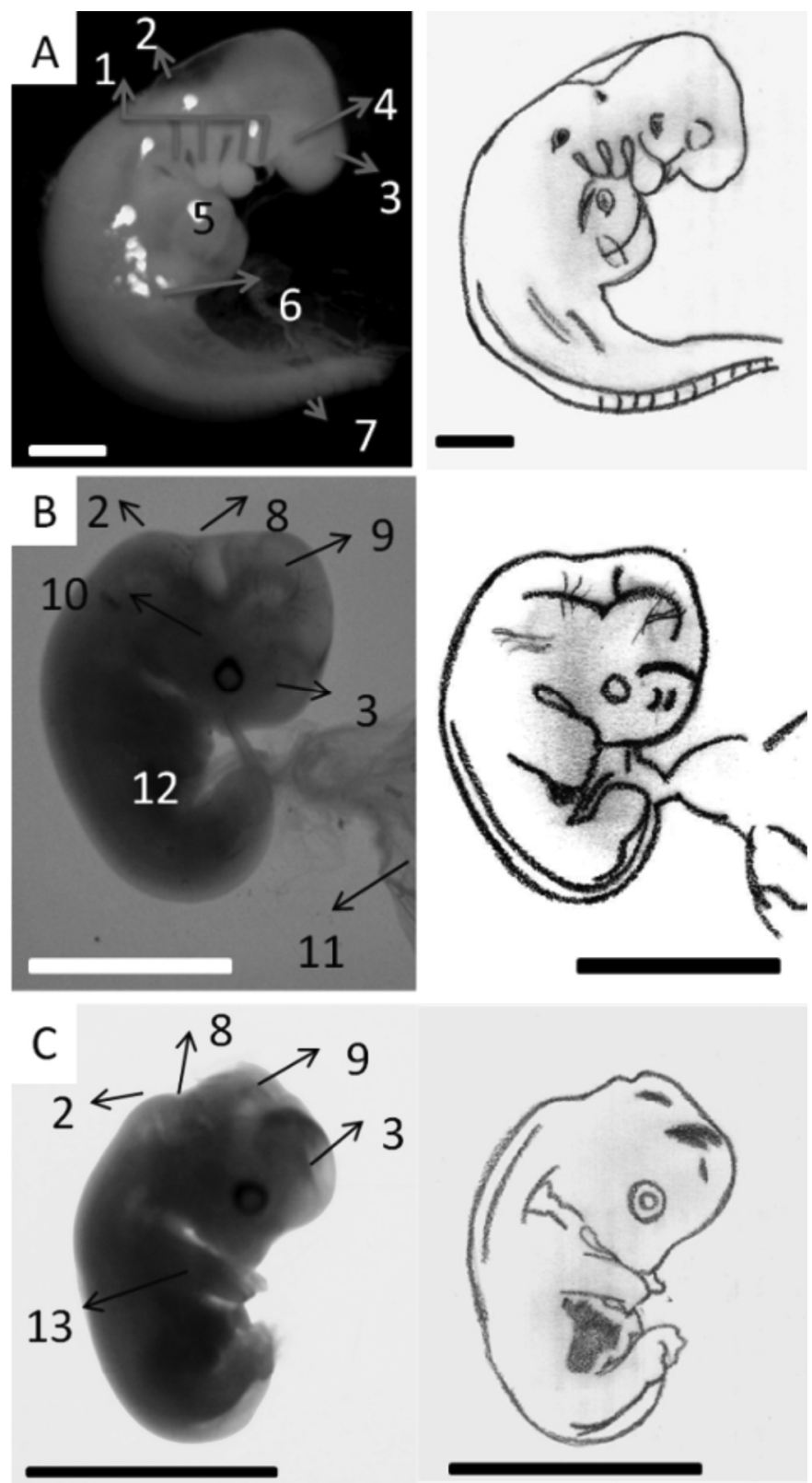

Fig.1. (A-C) Embrião de gato doméstico, em vista lateral, apresentado respectivamente $0,5 \mathrm{~cm}, 1,3 \mathrm{~cm}$ e $1,5 \mathrm{~cm}$ de $\mathrm{CR}$. Observar as estruturas: $1^{\circ}, 2^{\circ}, 3^{\circ}$ e $4^{\circ}$ arcos faríngeos (1), Flexura cervical (2), Prosencéfalo (3), Local placóide do cristalino (4), Proeminência cardíaca (5), Broto do membro pélvico (6), Somitos (7), Quarto ventrículo encefálico (8), Mesencéfalo (9), Vesícula ótica (10), Saco vitelino (11), Fígado (12), Membro torácico (13). (A) Barra: 0,1 cm. (B,C) Barra: 1,0cm. 
Os embriões E25 apresentam coloração rósea e a variação de CR foi de 1,3 a 1,5 cm. Na cabeça podemos notar a presença de prosencéfalo e mesencéfalo, notamos também a curvatura cervical pronunciada, vesícula óptica com forte pigmentação da retina. Os membros pélvico e torácico apresentam-se bem desenvolvidos, com distinção dos dígitos. Na cavidade abdominal, notamos o fígado bem pronunciado. Podemos notar uma redução da curvatura que proporciona o formato de "C" aos embriões, além da presença de uma projeção rostral (Fig.1C).

No feto (F52) constatamos o alongamento da região cervical e focinho, além de diferenciarmos facilmente as regiões anatômicas de felinos adultos, como a região caudal, esternal, abdominal, torácica, cranial dentre outras. Nessa fase notamos a presença de pêlos distribuídos por todo o corpo e pigmentação da pele. Na cabeça, observam-se cavidades oral e nasal bem delimitadas, externamente podendo ser identificados lábio superior e inferior e a fossa nasal. Também verificamos as pálpebras, o pavilhão auricular e a presença de pêlos táteis ao redor das bordas nasais (Fig.2A,B). Na cavidade torácica a visualização das costelas ficou impossibilitada devido ao espessamento da derme. 0 mesmo é válido para a cavidade abdominal, onde se torna impossível a visualização de vísceras. Notamos a presença de membros torácicos e pélvicos totalmente formados, o que inclui a presença dos dígitos individualizados e unhas, além de ser possível a distinção entre o sexo dos fetos (Fig.2A-D).

Ao explorar a topografia dos órgãos torácicos e abdominais de fetos de gatos domésticos com aproximadamente 52 dias de idade notamos que os mesmos encontram-se formados. As cavidades já se encontram dividas pelo diafragma sendo esse uma película fina de musculatura. $\mathrm{Na}$ cavidade torácica visualiza-se o coração, pulmão, traquéia e esôfago. A traquéia é formada por anéis cartilaginosos e adentra o parênquima pulmonar. A parte cervical do esôfago é a princípio medial e dorsal a traquéia, enquanto que a parte torácica continua nesta posição até a base do coração,

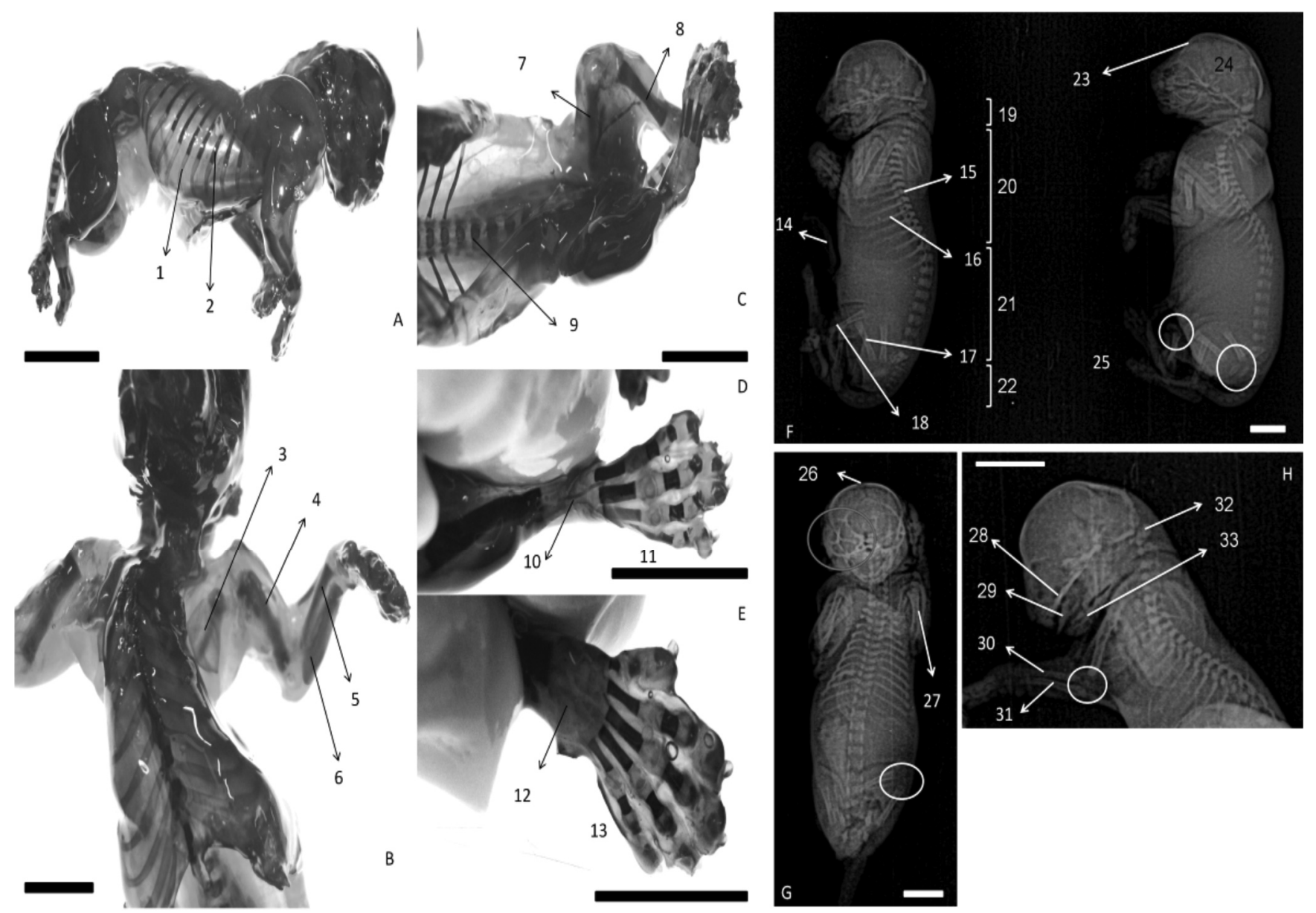

Fig.2. Vísceras do feto de gato doméstico com aprox. 52 dias de gestação. (A-D) Fetos de gatos domésticos, em vista lateral e ventrodorsal, com 52 dias de gestação. Observar as estruturas: Pálpebra superior (1), Pálpebra inferior (1'), Pavilhão auricular (2), Membro torácico (3), Cordão umbilical (4), Membro pélvico (5), Coxin digital (6), Vibrisas ao redor da borda nasal (7), Fossa Nasal (8), Unha (9), Vulva (10), Prepúcio (11), Bolsa testicular (12). (E-J) Fígado (13), Vesícula biliar (14), Ducto biliar (14'), Vascularização do estômago (15), Estômago (16), Alças intestinais (17), Reto (18), Curvatura maior do estômago (19), Fundo do estômago (20), Cárdia (21), Corpo do estômago (22), Curvatura menor do estômago (23), Antro pilórico (24), Pâncreas (25), Duodeno (26), Rim direito (27), Glândula adrenal (28), Hilo renal (29), Rim esquerdo (30), Aorta abdominal (31), Veia cava caudal (33), Vesícula urinária (34), Esôfago (35), Traquéia (36), Pulmão (37), porção cranial do lobo cranial esquerdo (38), porção caudal do lobo esquerdo (39), Lobo caudal esquerdo (40). Barra: $1 \mathrm{~cm}$. 
onde se inclina medialmente. No pulmão observam-se os lobos cranial, médio e caudal, além do acessório. Na cavidade abdominal notamos a presença do fígado e da vesícula biliar com o ducto biliar adentrando o parênquima hepático. No estômago observamos a presença do cárdia, corpo e fundo do estômago, curvatura maior, curvatura menor e antro pilórico. Observamos a presença das alças intestinais e do pâncreas caudal ao piloro. Ao remover o trato gastrointestinal notamos a presença dos rins definidos, com formato de grão de feijão, recostados a superfície dorsal da cavidade abdominal. No rim é possível identificar os pólos craniais e caudais e o hilo renal localizado no centro da borda medial. Visualiza-se a presença da aorta abdominal e da veia cava caudal (Fig.2E -J).

Pela técnica de alizarina,os fetos apresentaram diáfise calcificada em ossos longos como rádio, ulna, tíbia e fíbula. As costelas e falanges distais apresentaram ossificação e o esterno manteve-se cartilagíneo (Fig.3A-E).

Por meio do exame radiográfico, nota-se que os fetos (F52) não apresentaram nenhuma epífise óssea formada, entretanto podem-se visualizar as diáfises ósseas. $\mathrm{Na}$ cabeça notamos a presença da calota craniana com a fonta- nela aberta, a fossa orbitária e a massa encefálica, além da formação completa do platô dentário. Os eixos ósseos e articulares anatômicos encontram-se preservados e não foi possível avaliar nenhum órgão abdominal ou torácico. Os membros pélvicos e torácicos estão completamente formados. A região torácica possui 13 costelas. É visível a presença de 7 vértebras cervicais, 13 vértebras torácicas e 7 vértebras lombares, como é observado em um animal adulto (Fig.3F-H).

Microscopicamente, a fotomicrografia dos embriões de gatos domésticos com CR de $0,9 \mathrm{~cm}$ e idade gestacional estimada em 19 dias revelaram várias estruturas ao corte histológico longitudinal. Na cabeça notamos a presença do rostro, que dará origem à face, cavidade oral com lábio superior e inferior, cavidade nasal, olho e a abertura do $4^{\text {o }}$ ventrículo encefálico. Notamos a presença do esôfago, coração com átrio e ventrículo, pulmão, fígado, estômago, mesoderma esplâncnico, crista mesonéfrica e a gônada primitiva. Visualizamos ainda o broto do membro torácico, a coluna vertebral e a medula espinhal em formação (Fig.4).

Ao longo da extensão dorsal dos embriões estudados, visualizamos os somitos, com seus condroblastos que futu-

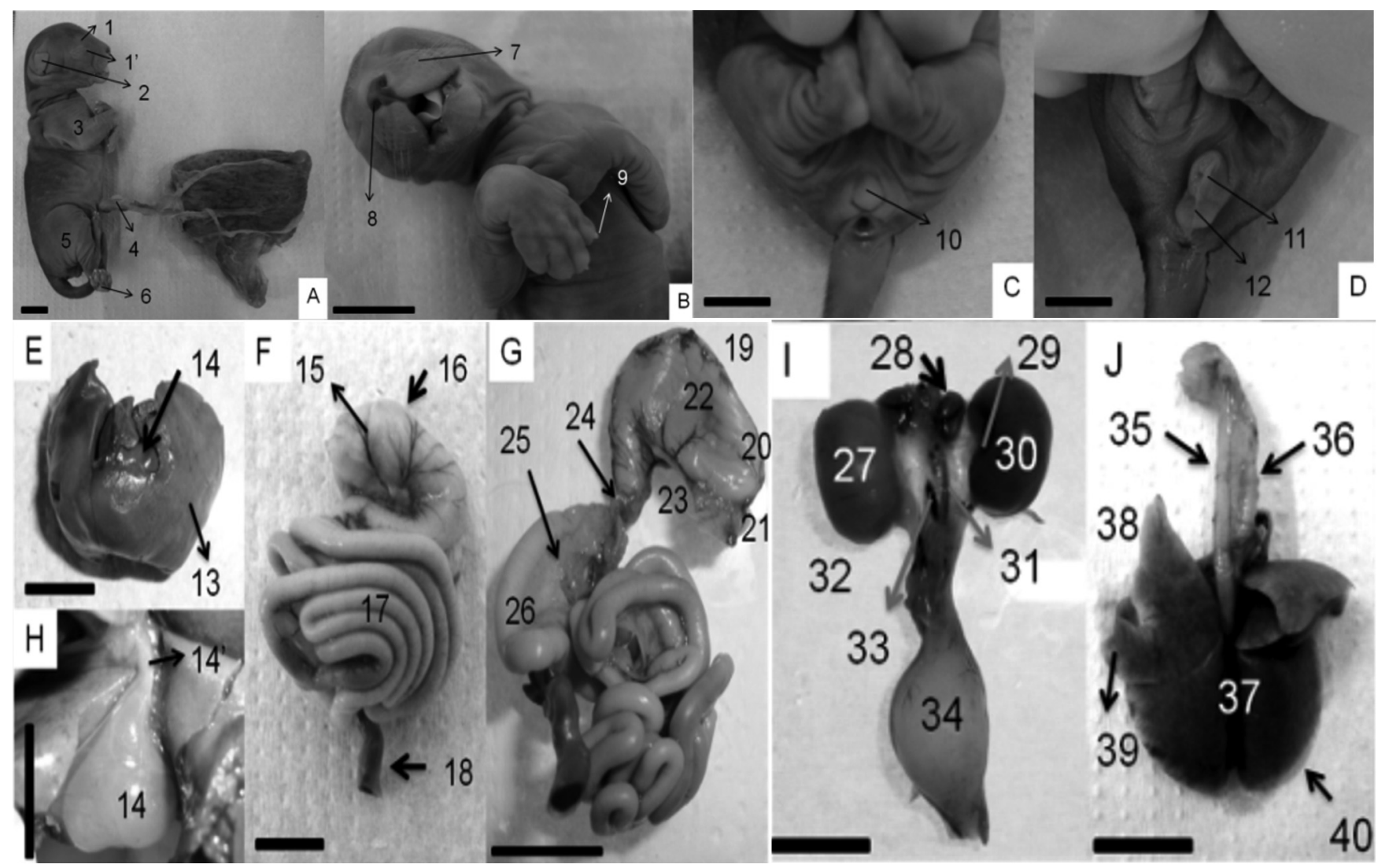

Fig.3. (A-E) Fetos de gatos domésticos com aprox. 52 dias de gestação, após a técnica de Alizarina. As regiões coradas em vermelho representam pontos de ossificação e as regiões coradas em azul, pontos cartilaginosos. Observar as estruturas: Esterno (1), Costela (2), Escápula (3), Úmero (4), Ulna (5), Rádio (6), Fêmur (7), Tíbia (8), Vértebras (9), Metatarso (10), Falanges proximal, medial e distal (11), Metacarpo (12), Falanges proximal, média e distal (13). Observar em F (posição laterolateral), G (posição ventrodorsal) e H (posição laterolateral), imagens radiográficas de fetos de gatos com 52 dias de gestação. Observar as estruturas: Cordão umbilical (14), Vértebras (15), Costelas (16), Fêmur (17), Tíbia (18), Vértebras cervicais, Vértebras torácicas (20), Vértebras lombares (21), Vértebras coccígeas2), Crânio (23), Massa encefálica (24), Membro Pélvico (25), Sínfise (26), Membro torácico (27), Maxila (28), Língua (29), Ulna (30), Rádio (31), Atlas (32), Mandíbula (33). Notar a ausência das epífises ósseas (círculos brancos) e a presença da fossa orbitária (círculo vermelho). Barra: $1 \mathrm{~cm}$. 
ramente se transformarão em corpos vertebrais. Entre os somitos temos tecido fibrocartilaginoso que originarão os músculos esqueléticos do tronco (Fig.4A).

Nos resultados expostos observamos a presença de tecido pulmonar que se estende no sentido caudal e longitudinal. Notamos que o pulmão irá entrar na fase pseudoglandular, com início das divisões dos lobos pulmonares. É possível visualizar o brônquio principal e secundário, bem como seu epitélio composto por várias camadas de células, apoiado em mesênquima ou tecido conjuntivo embrionário. Os brônquios estão circundados por vasos sanguíneos. Nessa fase não foram evidenciados estruturas semelhantes a alvéolos primitivos (Fig.4B).

Em análise microscópica podemos observar a presença de rins intermediários, chamados mesonefro. Visualizamos ainda a presença de túbulos contorcidos proximais, que apresentam orla em escova e túbulos contorcidos distal. Dorsal ao mesonefro, visualizamos uma gônada primitiva (Fig.4C).
Nos embriões estudados notamos a presença de duas câmaras cardíacas, uma atrial e outra ventricular. Visualizamos as camadas histológicas do coração: epicárdio, miocárdio e endocárdio, bem como formações trabeculares (Fig.4D).

Em nosso estudo, o fígado se apresenta dentro da cavidade abdominal, envolto por tecido conjuntivo embrionário. Apresenta epitélio revestimento sua luz e sua forma é tubular. Em embriões com estágio embrionário avançado, o fígado é o maior órgão em proporções se comparado ao tamanho total do embrião. 0 fígado resulta de um brotamento da porção caudal do tubo intestinal primitivo. Visualizamos as veias centro lobulares no parênquima hepático. Notamos o início da organização de hepatoblastos, e o início da formação dos cordões de hepatócitos. 0 fígado encontra-se envolto por uma fina camada serosa e apresenta início de lobulação (Fig.4E).

$\mathrm{Na}$ análise microscópica apenas o prosencéfalo foi observado nos embriões estudados, também foi notada a
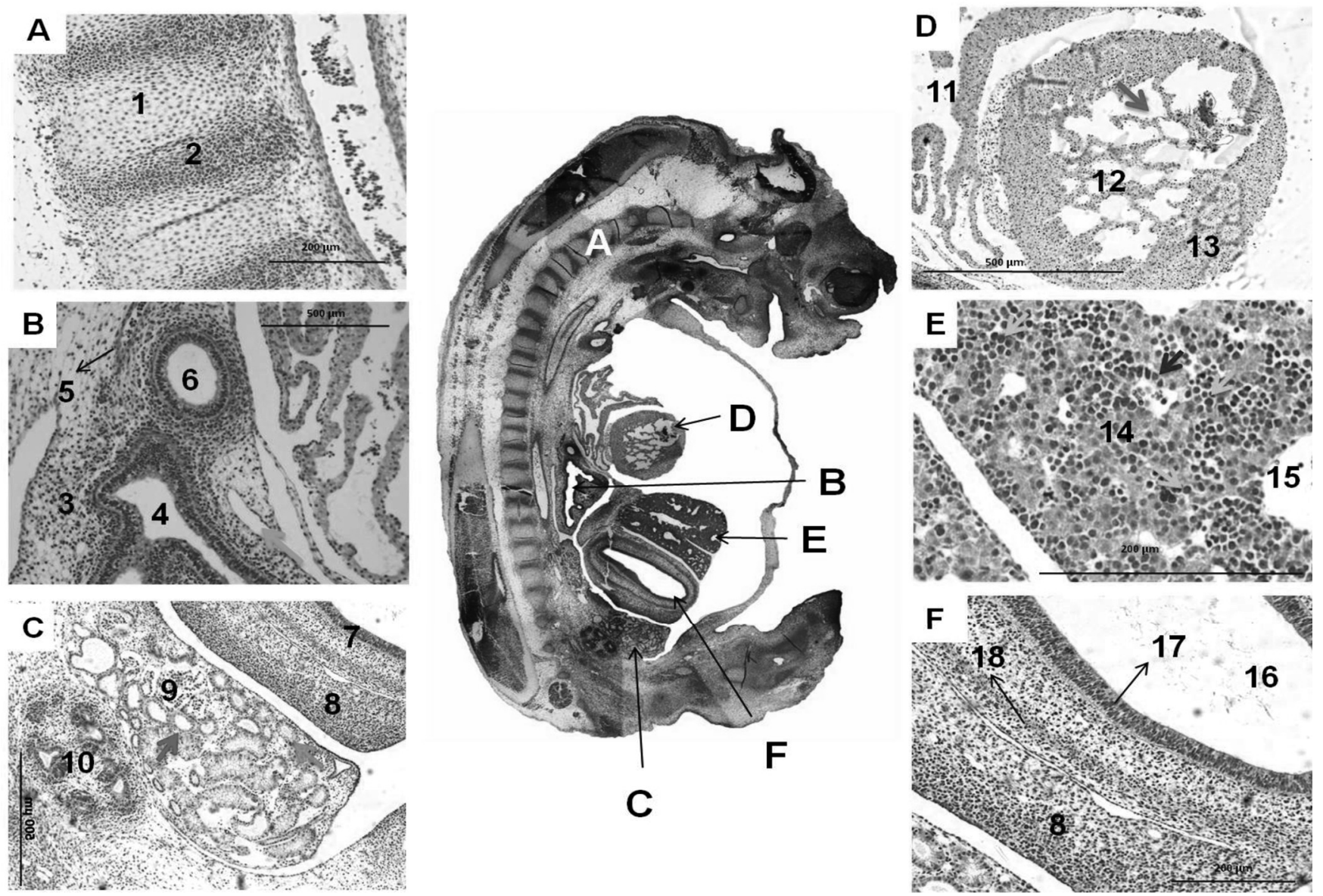

Fig.4. No centro, fotomicrografia do embrião de gato doméstico com vista lateral, apresentado aproximadamente 19 dias. Ao redor, observar as estruturas fotomicrografadas dos embriões. (A) Sistema músculo esquelético em aumento de 20x. Observar somitos (1) e tecido fibrocartilaginoso (2). (B) Corte do pulmão primitivo em aumento de 10x. Notar parênquima do pulmão primitivo (3), luz do brônquio primário (4), vaso sangüíneo (5), luz do brônquio secundário (6) e inicio da lobação pulmonar (seta verde). (C) Corte do rim (9) e gônada primitiva (10), destacando os túbulos contorcidos proximais (seta azul) e distais (seta vermelha). Acima, podemos notar o estômago (7) e o mesoderma esplâncnico (8). (D) Coração em aumento de 10x. Observar o átrio (11), o ventrículo (12) e a camada muscular que compõe o ventrículo (13). Na seta rosa, observar as trabéculas. (E) Corte do fígado em aumento de 40x. Notar o mesênquima hepático (14), a veia centro lobular (15), hepatócitos/hepatoblastos (setas laranja) e os cordões de hepatócitos (seta roxa). (F) Corte do estômago primitivo e do mesoderma esplâncnico (8). Observar a luz do tubo digestivo (16), epitélio de revestimento (17) e mesênquima (18). Coloração Hematoxilina-Eosina. 
presença da medula espinhal em formação, revestida por tecido conjuntivo. As vesículas ópticas de cada um dos lados do prosencéfalo originam o olho. Nos embriões analisados verificamos que o olho está em desenvolvimento e já apresenta delimitação bem como uma retina com nítida pigmentação (Fig.4).

Na avaliação microscópica dos órgãos do feto com idade estimada em 52 dias observamos a presença de estruturas internas muito semelhantes ao da vida adulta (Fig.3). A traquéia encontra-se revestida por epitélio colunar pseudo estratificado ciliado com a presença de células caliciformes, responsáveis pela secreção de muco. Na parede traqueal, é visível a presença de anéis de cartilagem hialina em forma de "C" e tecido conjuntivo (Fig.5A). Os pulmões já se encontram lobulados e nota-se a presença de alvéolos, sacos alveolares, bronquíolos e brônquios. Os alvéolos são estruturas presentes nos sacos alveolares, ductos alveolares e bronquíolos respiratórios, que possuem parede epitelial fina e apoiada em tecido conjuntivo. Neste tecido conjuntivo notamos uma rica rede de capilares sanguíneos. Os bronquíolos possuem epitélio cilíndrico simples ciliado, correspondendo às porções iniciais dos bronquíolos. Notamos a presença de células da clara nas paredes dos bronquíolos terminais. Estas células são responsáveis pela secreção de proteínas que protegem o revestimento bronquiolar contra inflamações ou poluentes (Fig.5A, D).

Em nosso estudo podemos observar uma espessa camada muscular na parede gástrica. Adicionalmente, notamos que sua luz é revestida por um epitélio que sofre invaginações formando as fossetas gástricas. Visualizamos uma camada de lâmina própria abaixo da mucosa e de glândulas na base do epitélio. Podemos observar o parênquima hepá-

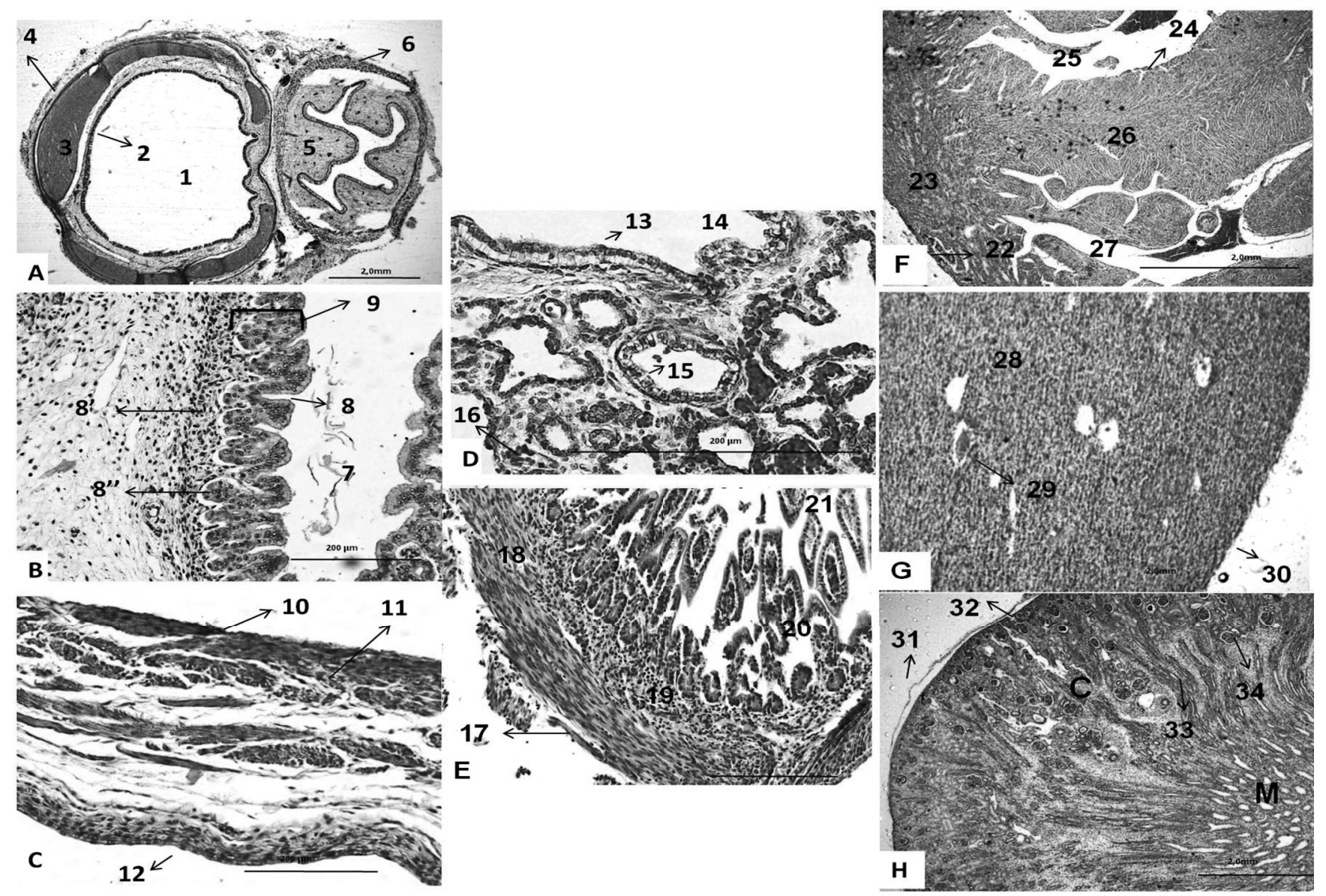

Fig.5. Fotomicrografias das vísceras do feto de gato com 52 dias de gestação. (A) Corte na região mediana do esôfago e traquéia, em aumento de $4 \mathrm{x}$, destacando a traquéia (à esquerda) e o esôfago (à direita). Observar as estruturas: lúmen traqueal (1), epitélio pseudoestratificado ciliado (2), cartilagem hialina (3), pericôndrio (4), submucosa do esôfago (5), muscular da mucosa (6). (B) Corte sagital do estômago (região glandular fúndica) em aumento 20x, destacando o lúmen (7), fosseta gástrica (8), lâmina própria (8'), glândulas (8”) e epitélio (9). (C) Corte sagital da vesícula urinária em aumento de 20x. Notar a serosa (10), camada muscular (11) e o epitélio de transição (12). (D) Corte sagital do pulmão, em aumento de 40x. Observar célula da Clara (13), bronquíolo (14), epitélio simples cúbico (15), vaso sangüíneo (16). (E) Corte sagital do jejuno, em aumento de 20x. Notar a serosa (17), camada muscular (18), submucosa (19), vilosidades (20) e lúmen intestinal (21). (F) Corte sagital do coração em aumento de 4x. Notar o pericárdio (22), miocárdio (23), endocárdio (24), ventrículo esquerdo (25), septo interventricular (26) e ventrículo direito (27). (G) Corte sagital do fígado em aumento de 10x. Observar o parênquima hepático (28), vaso sanguineo (29) e serosa (30). (H) Corte sagital do rim, em aumento de 4x. Notar a região cortical (C) e medular (M) que compõem a estrutura renal. Observar a cápsula renal (31), ducto papilar (32), túbulo contorcido (33) e glomérulo (34). Coloração Hematoxilina-Eosina. 
tico envolto pela a serosa, e a presença de vasos sanguíneos, sinusóide e hepatócitos (Fig.5B).

$\mathrm{Na}$ análise microscópica do intestino visualizou-se o lúmen intestinal repleto de vilosidades, que são projeções alongadas da mucosa em direção a luz do órgão. Notamos a presença da mucosa de revestimento formada por células epiteliais colunares que possuem característica absortiva, intercaladas com células caliciformes responsáveis pela secreção de muco. Entre as vilosidades podemos notar as criptas de Lieberkühn que são discretas aberturas de glândulas tubulares simples. Observamos ainda que a mucosa encontra-se apoiada na submucosa e esta em uma camada muscular. 0 órgão encontra-se revestido externamente por uma serosa (Fig.5E).

Nos fetos estudados, os rins apresentam forma de grão de feijão, apresentado uma face convexa e outra côncava, onde localizamos o hilo renal. É pelo hilo renal que entram e saem os vasos sanguíneos, nervos e o ureter. 0 rim do feto estudado apresenta-se muito semelhante ao órgão em adultos (Fig.2I). Na análise microscópica foi possível identificar a zona medular e cortical. Notamos a presença da cápsula renal envolvendo o órgão e dos túbulos contorcidos proximais, que possuem um epitélio com células que contém um citoplasma apical com microvilos, formando uma "orla em escova". Visualizamos os túbulos contorcidos distais e os glomérulos. (Fig.5H).

$\mathrm{Na}$ análise microscópica da bexiga fetal, notamos a presença de um epitélio de transição na luz do órgão, apoiado na lamina própria. Além dessas estruturas, visualizamos a presença de uma camada muscular e da serosa. Quando a bexiga esta repleta de urina as células deslizam umas sobre as outras, tornando o epitélio mais delgado. Entretanto, quando a bexiga está vazia a membrana se dobra nas regiões delgadas e se invaginam (Fig.5C).

Na microscopia do coração, notamos a presença das três camadas compondo sua parede: epicárdio, miocárdio e endocárdio. Visualizamos a presença dos dois átrios e dos dois ventrículos, sendo que a parede muscular ventricular esquerda é mais espessa que a direita e a presença de um septo entre elas (Fig.5F).

\section{DISCUSSÃO}

A embriologia compreende o conhecimento relativo ao início da vida e às mudanças que ocorrem durante o desenvolvimento pré-natal (Moore \& Persaud 2007). De acordo com Beaudoin et al. (2003), a embriogênese de algumas espécies está correlacionada com uma série de mudanças contínuas, de uma maneira similar a que ocorre no desenvolvimento pré-natal nas diferentes espécies. Em geral, a descrição do desenvolvimento embrionário e fetal em outras espécies foi baseada em estágios construídos através da idade, mudanças corporais por diferenciação gradual, aumento do tamanho do corpo e peso, e desenvolvimento total de sistemas e órgãos (Knospe 2002, Beaudoin et al. 2003, Ambrósio et al. 2002, Miglino et al. 2006).

Segundo estudo realizado por Evans \& Sack (1973) o período embrionário dos gatos inicia-se no momento da implantação e vai até o vigésimo oitavo dia gestacional. A partir do vigésimo nono dia gestacional até o momento do nascimento é denominado de período fetal, sendo que o período gestacional dos gatos domésticos pode variar de 58 a 65 dias apresentando uma média de 62 dias (Hyttel et al. 2009).

Na análise macroscópica dos embriões e fetos de gatos domésticos o período gestacional foi estimado pelo do Crown-Rump, de acordo com os dados da curva de crescimento descrito por Evans \& Sack (1973).

Nos embriões de gatos com idade estimada em 17 dias, a coloração translúcida permitiu a visualização de estruturas internas, como o coração, o prosencéfalo e a flexura cervical, além da presença dos quatro arcos faríngeos e da vesícula ótica, corroborando com os relatos de Evans \& Sack (1973) e de Hyttel et al. (2009). Diferentemente dos gatos, os cães apresentam o quarto arco faríngeo apenas aos 25 dias de gestação (Evans e Sack, 1973).

Em embriões com 22 dias de idade gestacional podemos observar a presença da vesícula óptica, retina pigmentada, ranhura superficial entre os dígitos. Essas estruturas podem ser observadas no embrião com $1,2 \mathrm{~cm}$ de CR onde a coloração translúcida permite a visualização de estruturas internas, como as vesículas encefálicas, a curvatura cervical e a vascularização superficial. De acordo com Evans \& Sack (1973), essas mesmas estruturas são evidenciadas em embriões caninos a partir do $25^{\circ}$ ao $28^{\circ}$ dia gestacional.

Em nossos estudos foi verificado que embriões de gatos domésticos com 25 dias de gestação apresentam uma curvatura cervical pronunciada, vesícula óptica, vesícula ótica, fígado bem pronunciado, membros pélvicos e torácicos bem desenvolvidos, com distinção dos dígitos e apresentando projeção rostral. Esses achados corroboram com o descrito por Evans \& Sack (1973) em trabalhos sobre o desenvolvimento pré-natal de mamíferos domésticos, os quais citam que embriões felinos entre 24 e 26 dias de gestação apresentam tais estruturas. Segundo Sadler (2005) do $24^{\circ}$ ao $25^{\circ}$ dia de gestação, embriões humanos possuem as vesículas e placóides ópticos formadas, e seus somitos já são em número de 13 a 20.0 mesmo autor descreve que em embriões humanos entre 36 e 40 dias de gestação apresentam uma acentuada curvatura cervical semelhante à encontrada em embriões de gatos com 25 dias.

Em fetos com 52 dias de gestação foi possível observar estruturas muito parecidas com aquelas encontradas nos animais adultos. Assim notamos a presença de pele pigmentada, pálpebras superior e inferior, pavilhão auricular formado, cavidades oral e nasal bem delimitadas, presença de pêlos táteis, presença de dígitos bem delineados com garras duras e esbranquiçadas. Todas essas alterações são descritas por Evans \& Sack (1973) em fetos de gatos a partir de 50 dias de gestação.

Baseado em Bacha Jr \& Bacha (2004) os fetos estudados possuem órgãos formados com estruturas semelhantes a animais adultos. As estruturas ósseas já são observadas no exame radiográfico e técnica de alizarina. De acordo com Sorribas (2006), a visualização dessas estruturas no exame radiográfico ocorre a partir dos 45 dias gestacionais.

Para o estudo histológico de embriões com 19 dias de gestação, utilizamos como parâmetro a descrição dos órgãos humanos realizada por Junqueira \& Carneiro (2004) e 
de animais realizado por Bacha Jr \& Bacha (2003). De acordo com Moore \& Persaud (2007) a formação da medula em humanos, ocorre a partir do tubo neural. Segundo Hoar \& Monie (1981) a visualização das vesículas cerebrais em humanos ocorre com quatro semanas. Em nossas análises histológicas visualizamos a presença do prosencéfalo e das vesículas ópticas em formação.

Em embriões de gatos com 19 dias gestacionais verificamos que os somitos tendem a formar placas ovaladas de tecido cartilagíneo. Os somitos são formações de tecido epitelial condensado que darão origem aos corpos vertebrais. As vértebras serão responsáveis pela proteção da medula espinhal do animal, por essa razão se explicam a condensação de células (Sadler 2005). Em nosso estudo visualizamos no embrião com 19 dias de gestação os somitos com seus condroblastos de acordo com Evans \& Sack (1973) a partir de 13 dias de gestação de gatos os somitos iniciam sua formação.

O aparelho respiratório é constituído pelos pulmões e um sistema de tubos que comunicam o parênquima pulmonar com o meio exterior (Junqueira \& Carneiro 2004). Nos embriões de gatos domésticos com 19 dias de gestação notamos que o pulmão irá entrar na fase pseudoglandular, com início das divisões dos lobos pulmonares. Observamos a presença do brônquio principal e secundário. $\mathrm{Na}$ espécie humana com 28 dias de gestação ocorre o início da formação do aparelho respiratório inferior. Durante o período embrionário humano, o pulmão encontra-se em fase pseudoglandular, quando se formam os brônquios e bronquíolos terminais (Moore \& Persaud 2007). Já nos fetos de gatos domésticos com 52 dias de gestação, a traquéia e o pulmão se encontram lobulados e apresentam alvéolos, sacos alveolares, bronquíolos e brônquios. As estruturas identificadas coincidem com aquelas citados por Junqueira \& Carneiro (2004).

O sistema vascular é composto pelo coração, as artérias, os vasos capilares e as veias. 0 coração é um órgão muscular responsável por bombear o sangue através dos vasos sanguíneos (Junqueira \& Carneiro 2004). Em humanos, o coração e o sistema vascular surgem por volta da terceira semana do desenvolvimento embrionário, sendo derivado do mesoderma esplâncnico. 0 coração propriamente dito inicia suas funções na quarta semana, esse desenvolvimento precoce é necessário porque o embrião necessita de um suporte nutricional acentuado, que não é suprido apenas com a difusão (Moore \& Persaud 2007). Em nossos resultados observamos que o coração de embriões com 19 dias gestacionais, é constituído de cardiomioblastos e capilares, e apresenta duas câmaras cardíacas, uma atrial e outra ventricular, com as camadas que compõem sua parede (epicárdio, miocárdio e endocárdio). Visualizamos a presença de cardiomioblastos que são precursores das fibras musculares cardíacas. Já no coração dos fetos de gatos domésticos com 52 dias de gestação podemos notar a presença deparede muscular espessa constituída por cardiomiócitos, como observada em animais adultos (Bacha Jr \& Bacha 2004). Destaca-se ainda a presença de quatro câmaras cardíacas, sendo duas atriais e duas ventriculares, separadas por válvulas.
O sistema digestório compreende a cavidade oral, esôfago, estômago, intestinos delgado e grosso, glândulas salivares, fígado e pâncreas. Sua função é obter, através dos alimentos ingeridos, os nutrientes necessários para suprir a demanda energética do organismo (Bacha \& Bacha Jr 2003; Junqueira \& Carneiro 2004). O estômago é um segmento dilatado, cuja função principal é transformar o bolo alimentar em uma massa viscosa por meio da atividade muscular e química. Desta forma é responsável pela digestão parcial dos alimentos e secreção de enzimas e hormônios (Junqueira \& Carneiro 2004). Nos embriões estudados, o esôfago primitivo possui uma camada muscular e se alonga com a descida do coração, corroborando com os resultados descritos em humanos por Moore \& Persaud (2007). Na análise microscópica do esôfago fetal, foi possível observar a presença de estruturas bem delimitadas semelhantes às encontradas em animais adultos.

Segundo Moore \& Persaud (2007) o surgimento do estômago em embriões da espécie humana se dá na quarta semana de gestação, aparecendo como uma dilatação fusiforme do intestino anterior. Durante as semanas subsequentes, sua aparência e posição se modificam, em consequência das diferentes razões do crescimento em diversas regiões de sua parede e das alterações na posição dos órgãos circundantes. Em nosso estudo, o mesmo se apresenta dentro da cavidade abdominal, envolto por tecido conjuntivo embrionário nos embriões com 19 dias de gestação. Entretanto, nos fetos de gatos domésticos com 52 dias de gestação observamos a mucosa, submucosa, fosseta gástrica, glândulas e camada muscular como pode ser observado em animais adultos (Junqueira \& Carneiro 2004).

0 fígado é o segundo maior órgão do corpo e está situado na cavidade abdominal abaixo do diafragma. 0 fígado realiza uma interface entre o sistema digestório e o sangue, pois é o órgão no qual os nutrientes absorvidos são processados e armazenados para utilização por outros órgãos (Barcha \& Barcha Jr 2003, Junqueira \& Carneiro 2004). O fígado surge por volta da terceira semana em humanos como uma evaginação do epitélio endodérmico, na extremidade distal do intestino anterior (Sadler 2005). Em nossos resultados foram observados no fígado embrionário a presença de hepatoblastos, da veia porta e veias centro lobulares. $\mathrm{Na}$ fase embrionária o fígado não apresentou-se lobulado, em contrapartida, no fígado fetal notamos a presença de s de hepatócitos no parênquima, bem como as lobulações que persistirão durante a fase adulta.

0 intestino delgado é o sítio terminal de digestão dos alimentos, absorção de nutrientes e secreção endócrina (Junqueira \& Carneiro 2004). De acordo com Junqueira \& Carneiro (2004) e Moore \& Persaud (2007) o desenvolvimento intestinal caracteriza-se pelo alongamento rápido do intestino primitivo e seu mesentério resultando na formação da alça intestinal primária. Os fetos estudados apresentaram todas as alças intestinais formadas, repletas de vilosidades em seu lúmen, como é visto em felinos adultos (Junqueira \& Carneiro 2004).

O sistema urinário é formado pelos rins, ureteres, bexiga e uretra. Desta forma, a urina formada nos rins é conduzida até a bexiga pelos ureteres e da bexiga a urina é 
lançada para o meio exterior pela uretra (Junqueira \& Carneiro 2004). Segundo Moore \& Persaud (2007) o sistema urinário na espécie humana se desenvolve a partir do mesoderma intermediário, que se estende ao longo da parede dorsal do corpo do embrião. Esse mesoderma é deslocado e perde sua conexão durante o dobramento do embrião no plano horizontal. Uma elevação se forma em cada lado da aorta dorsal, dando origem à parte do sistema urinário e genital. 0 primeiro conjunto de rins é o pronefron, em seguida temos o mesonefro e o terceiro conjunto é o metanefro, que se tornará o rim permanente (Sadler 2005). De acordo com essa classificação estudada para humanos, os embriões de gatos domésticos com 19 dias de idade, apresentaram rim intermediário ou mesonefro. Já no feto com 52 dias de idade, observamos os rins permanentes com a presença de cortical e medular além de estruturas bem delimitadas.

Contudo, nesse trabalho podemos observar que fetos com 52 dias de idade gestacional, não apresentaram nenhuma formação das epífises ósseas. Entretanto, foi possível visualizar as diáfises ósseas, com a presença das regiões cortical e medular bem definidas as quais foram analisadas pelas técnicas de Alizarina e imagens radiográficas.

Em nosso estudo sobre o desenvolvimento embrionário e fetal em gatos domésticos podemos concluir que as estruturas internas e externas encontradas em fetos com idade gestacional estimada em 52 dias são semelhantes às de animais adultos e as estruturas ósseas já possuem áreas de calcificação.

Agradecimentos.- Aos colegas do Setor de Anatomia, pela valiosa ajuda neste trabalho, João Carlos Morini Júnior e Márcio Nogueira Rodrigues.

\section{REFERÊNCIAS}

Ambrósio C.E., Miglino M.A., Lima A.R., Martins D.S., Assis-Neto A.C., Bonatellil M., Verechia F.T. \& Carvalho A.F. 2002. Placental fissure in mongrel cats, Felis catus Linnaeus, 1758. Gross and microscopical aspects. Braz. J. Vet. Res. Anim. Sci. 41(2):81-85.

Bacha Jr W.J. \& Bacha L.M. 2003. Atlas Colorido de Histologia Veterinária. $2^{\text {a }}$ ed. Roca, Sẵo.Pagulǫ.

Beaudoin S., Barbet P. \& Bargy F. 2003. Developmental stages in the rabbit embryo: Guidelines to hoose an appropriate experimental model. Fetal Diagn. Ther. 18:422-427.

Evans H.E. \& Sack W.O. 1973. Prenatal development of domestic and laboratory mammals: growthcurves, external features and selected references. Anatomy, Histology and Embryology. Zentralbl. Veterinärmed. 2(1):11-45.

Hyttel P., Carlsson G.L., Scott Heller R. \& Serup P. 2009. Immunohistochemistry of Pancreatic Development in Cattle and Pig. Anat. Histol. Embryol. 39(2):107-119.

Hyttel P, Sinowatz F \& Vejlsted M 2010. Domestic Animal Embryology. 11tlh ed. Saunders, Elsevier, p.359

Hoar R.M. \& Monie I.W. 1981. Comparative development of specific organ systems, p.13-33. . In: (Kimmel C.A. \& Buelke-Sam J. (Eds), Developmental Toxicology Raven Press, New York.

Junqueira L.C. \& Carneiro J. 2004. Histologia Básica. 10aㅡ ed. Guanabara Koogan, Rio de Janeiro.

Knospe C. 2002. Periods and stages of the prenatal development of the domestic cat. Anat. Histol. Embryol. 31(1):37-51.

Martins D.S., Ambrósio C.E., Saraiva N.Z., Wenceslau C.V., Morini A.C., KerKis I., Garcia J.M. \& Miglino M.A. 2011. Early development and putative primordial germ cells characterization in dogs. Reprod. Domest. Anim. 46(1):62-66. doi: 10.1111/j.1439-0531.2010.01631.x.

Moore K.L. \& Persaud T.V.N. 2007. Embriologia Clínica, 7a ed. Elsevier, Rio de Janeiro. 536p.

Migaki G. 1982. Compendium of inherited metabolic diseases in animals. Progr. Clin. Biol. Res. 94:473-501.

Miglino M.A., Ambrosio C.E., Martins D.S., Pfarrer C. \& Leiser R. 2006. The carnivore pregnancy: the development of the embryo and fetal membranes. Theriogenology 66:1699-1702.

Sadler T.W. 2005. Langman Embriologia Médica. 9ạ ed. Guanabara Koogan, Rio de Janeiro, p.3-77.

Sorribas C.E. 2006. Atlas de Reprodução Canina. Interbook, São Caetano do Sul, p.348.

Wilson D.E. \& Reeder D.M. 2005. Mammal Species of the World. Vol.2. Johns Hopkins University Press, Baltimore, p.142. 